DOI: $10.25100 /$ pfilosofica.v0i50.8837

\title{
GRAMÁTICAS DEL ODIO EN EL CAPITALISMO CONTEMPORÁNEO. UNA LECTURA DESDE SPINOZA
}

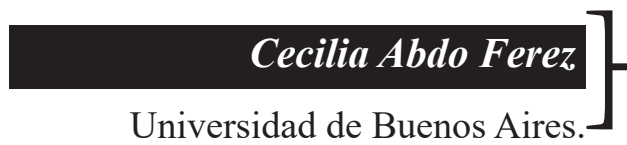

Universidad Nacional de las Artes, Consejo Nacional de Investigaciones

Científicas y Técnicas, Buenos Aires, Argentina.

\begin{abstract}
Resumen
El artículo retoma la perspectiva de F. Lordon, en su lectura de B. de Spinoza, para comprender fenómenos políticos contemporáneos: ¿cómo se configura el deseo, en el neoliberalismo? Se plantea como hipótesis que el neoliberalismo combina dos tipos de movimientos de lo que, en términos spinocistas, se llamaría odio. Por un lado, produce un afecto de abyección, una adaptación de los deseos a la imagen menospreciada de sí. Por el otro, al sumar a lo anterior una diversificación y fragmentación en extremo de las experiencias laborales, el neoliberalismo quiebra las experiencias comunes, esto es, las afecciones comunes, invalidando la producción de una cadena de indignación lo suficientemente intensa y perdurable como para generar un trastrocamiento institucional progresista (entendiendo por ello, una reforma institucional contraria al neoliberalismo, que reponga la centralidad de los derechos sociales). Es decir, aun cuando haya muchas personas vulnerabilizadas, precarizadas, etc., es dificil que ese sinnúmero pueda proyectarse y actuar como semejantes durante un tiempo perdurable, porque se bloquea la producción de una identidad común.
\end{abstract}

Palabras clave: indignación; odio social; neoliberalismo; teoría de la regulación; crisis

Cómo citar este artículo: Abdo Ferez, C. (2020). Gramáticas del odio en el capitalismo contemporáneo. Una lectura desde Spinoza. Praxis Filosófica, (50S), 43-58. doi: 10.25100/pfilosofica.v0i50.8837.

Recibido: 21 de agosto de 2019. Aprobado: 3 de octubre de 2019 . 


\title{
Grammar of Hate in Contemporary Capitalism. A Reading from Spinoza
}

\author{
Cecilia Abdo Ferez ${ }^{1}$
}

\begin{abstract}
The article goes back to F. Lordon, in his reading of B. de Spinoza, to understand contemporary political phenomena: how is desire configured, in neoliberalism? It is hypothesized that neoliberalism combines two types of movements of what, in spinocist terms, would be called hate. On the one hand, it produces an affect of abjection, an adaptation of desires to the belittled image of itself. On the other, added to the last, by diversifying and fragmenting work experiences in the extreme, neoliberalism intervenes on common experiences, that is, on common affections, invalidating the production of a chain of indignation intense and lasting enough to generate an institutional uproar in a progressive sense (that means: an institutional uproar contrary to neoliberalism, which guarantees social rights). That is, even if there is a lot of vulnerability, precariousness, etc., it is difficult for those many to project themselves and act as alike, for an enduring time, because the production of a common identity is blocked.
\end{abstract}

Keywords: Indignation; Social Hate; Neoliberalism; Theory of Regulation; Crisis.

${ }^{1}$ Licenciada en Ciencia Política por la Universidad de Buenos Aires (UBA), Argentina, y Dr. phil. por la Facultad de Filosofía III de la Universidad Humboldt de Berlín, Alemania. Es investigadora independiente del Consejo Nacional de Investigaciones Científicas y Técnicas (CONICET), Argentina, en el área de Teoría Política Moderna y se dedica en particular a la filosofía de Baruj de Spinoza y otros materialismos del siglo XVII. Es profesora adjunta interina de la materia "Teoría Política y Social II, en la Facultad de Ciencias Sociales de la UBA y titular concursada de la materia "Filosofía", en el Departamento de Artes Visuales de la Universidad Nacional de Artes (UNA). Codirige el Programa de Posgrado en Estudios Políticos (UBA-FSoC). Su libro último, en prensa, es Spinoza contra las mujeres, Antígona, Madrid, 2019.

ORCID: 0000-0003-1270-4497 E-mail: ceciliaabdo@conicet.gov.ar 


\title{
GRAMÁTICAS DEL ODIO EN EL CAPITALISMO CONTEMPORÁNEO. UNA LECTURA DESDE SPINOZA*
}

\author{
Cecilia Abdo Ferez \\ Universidad de Buenos Aires. \\ Universidad Nacional de las Artes, Consejo Nacional de Investigaciones \\ Científicas y Técnicas, Buenos Aires, Argentina.
}

En un cruce entre ciencias sociales y filosofía, o más específicamente, entre la teoría de la regulación económica y la filosofía de Baruj de Spinoza, Frédéric Lordon dice que las estructuras del régimen de acumulación "se expresan" bajo la especie de un cierto régimen de afectos y deseos. Esto es, el régimen de afectos y deseos de una determinada sociedad y de los individuos que la componen, "llega como a duplicar" las estructuras económicas del régimen de acumulación (Lordon, 2018, p. 96). Así, por ejemplo, la introducción del fordismo habría producido una reestructuración del complejo pasional de los asalariados, agregando a los afectos tristes del dominio, presentes en cualquier relación laboral, los afectos alegres, que propiciaba el consumo en masa. Dice Lordon:

La liberación del deseo adquisitivo, [...], es al principio una reestructuración muy profunda de la complexión pasional del asalariado, llevado no sólo a sufrir la movilización coercitiva bajo el aguijón del hambre sino también a gozar de las alegrías de la mercancía, por cierto a un grado de apego del cual se sabe ahora que habrá otorgado al capitalismo un superávit de adhesión que Marx no podía imaginar, y por eso, también uno de sus anclajes políticos más sólidos (Lordon, 2018, p. 285).

Siguiendo este esquema de interpretación, cada cambio histórico en el régimen de acumulación, o, para decirlo con otras palabras, cada nueva

\footnotetext{
*Este texto se presentó, como ponencia y en versión modificada, en el XV Coloquio Internacional Spinoza de Ascochinga, Córdoba, Argentina, en 2018.
} 
etapa del capitalismo, generaría su reestructuración del complejo de afectos y deseos sociales, también ellos, históricamente mutables. Esto daría forma al deseo. El deseo no sería así el impulso que solemos representarnos como si fuese espontáneamente dirigido, sino que, leído desde la célebre definición de Spinoza en Ética III, 9, deseo es la determinación a actuar, determinación que (también, pero no sólo) provendría de las estructuras e instituciones del régimen de acumulación. Para decirlo en términos spinocistas: el deseo es la determinación del conatus a hacer algo o, lo que es igual, la determinación a actuar de esa fuerza o potencia por persistir en la existencia, que define la esencia de cada individuo (Spinoza, [1675] 1980). El deseo, o esencia dinámica que define a cada quién, es siempre en acto. Tanto cuando se padece como cuando se actúa, se está deseando, se está esforzándose por continuar existiendo. En los individuos humanos en particular, Spinoza iguala al deseo con el apetito, pero le agrega la conciencia del apetito (E III, 9, esc.). Esa conciencia, como dirá Étienne Balibar, es sólo la diferencia entre apetito y deseo o "lo específicamente humano" (Balibar, 2016, p. 12), pero no lo primordial, porque como se dice en la explicación de la primera definición de los afectos, "tenga o no tenga el hombre conciencia de su apetito, dicho apetito sigue siendo, de todas maneras, el mismo". Escribe Spinoza en el escolio de E III, 9, sobre el esfuerzo por perseverar en su ser:

Este esfuerzo, cuando se refiere al alma sola, se llama voluntad, pero cuando se refiere a la vez al alma y al cuerpo, se llama apetito; por ende, éste no es otra cosa que la esencia misma del hombre, de cuya naturaleza se siguen para su conservación cosas que, por tanto, el hombre está determinado a realizar.

Y resume en la definición de los afectos 1 de la parte III: "El deseo es la esencia misma del hombre en cuanto es concebida como determinada a hacer algo en virtud de una afección cualquiera que se da en ella".

El deseo abarca todo esfuerzo, mental y corporal, por perseverar en la existencia. Pero, por sí, es indeterminado, sin objeto, intransitivo, sin falta, sin finalidad (Bove, 2010; Chaui, 2011). La determinación del deseo se da por las afecciones, que es como Spinoza llama a las modificaciones del conatus que producen las interacciones con otros cuerpos. Estas afecciones le marcan una dirección, un objeto, o reformulan al deseo según una determinación actual. En ese sentido, el deseo es siempre la esencia de cada quien, modificada por las interacciones con otros. O, como dirá De Pablos Escalante, hay una alteridad constitutiva del deseo (De Pablos Escalante, 2018 , p. 250). Esto no significa que el deseo sea deseo de otro sin más, sino 
deseo modelado por la existencia de los otros, en relación con la nuestra. El deseo es relacional y marcado por la pluralidad de los demás y por la trama de nuestros encuentros con ellos.

Lordon afirma que "nadie se esforzó más que Spinoza en plantear la heteronomía del deseo como una absoluta generalidad" (Lordon, 2015, p. 35). El deseo es un flujo indefinido, pero cuyos objetos van a imponérsele inmediatamente desde fuera. El mismo trabajo ético consiste en reelaborar esas inmediatas dependencias, para poder desear también racionalmente, o, en otras palabras, para poder desear teniéndose a sí mismo como causa adecuada del actuar. Pero ese trabajo por imbricar razón y deseo es un proceso vital, sin garantías de éxito y, en el mejor de los casos, con interrupciones e intermitencias. En principio, la vida pasional se impone al individuo, como una multitud de objetos que capturan el deseo (es decir, la esencia y el actuar de cada quién) y le imponen una dinámica de la que se puede tener conciencia, pero una conciencia limitada. Esto es, se cree que se desea aquello que se autodetermina a desear, sin ver la causa de aquello que aparece como autodeterminación. Dice Lordon:

«El deseo -dice toda la primera definición de los afectos- es la esencia misma del hombre en tanto que es concebida como determinada a hacer algo por una afección cualquiera de sí misma». La fórmula es tan oscura como la de la perseverancia en el ser, y sin embargo dice exactamente lo que hace falta entender: la esencia del hombre, que es potencia de actividad, pero por así decirlo genérica, y como tal intransitiva, fuerza pura de deseo pero que no sabe todavía qué desear, no se convertirá en actividad más que por el efecto de una afección antecedente -un algo que le sucede y la modifica-, una afección que le designará una dirección y un objeto sobre los cuales ejercerse in concreto. Resulta de allí una inversión radical de la concepción ordinaria del deseo como tracción por un deseable preexistente. Es más bien el empuje del conatus lo que inviste las cosas y las instituye como objetos de deseo. Y estos investimentos están enteramente determinados por el juego de los afectos. Una afección -algo que adviene-, un afecto -el efecto en uno, triste o alegre, de la afección-, las ganas de hacer algo que de allí derivan -poseer, huir, destruir, perseguir, etcétera: la vida del deseo se elabora a partir de esta secuencia elemental- $(2015$, p. 35, 36).

Siguiendo la lectura de Lordon, en los cuerpos, en los deseos determinados de cada individuo, en sus acciones y pasiones, se expresaría la estructura del régimen de acumulación, originando una serie de refracciones o variaciones en esa determinación, de acuerdo a los complejos pasionales que son esos mismos cuerpos (de acuerdo a sus historias particulares, a sus 
entramados colectivos, a sus marcas o vestigia de otros cuerpos en él, etc.). Que en los cuerpos se exprese el régimen de acumulación significa que él modela incluso los gestos que hace el cuerpo deseante tanto del trabajador como de la trabajadora (de qué modo se mueve, qué conductas desarrolla, qué aspiraciones tiene y cuáles desecha, cuál es su cadencia al caminar de mañana y cuál de tarde, etc.). Incluso esas gestualidades corporales serían una producción común, que podría generar un reconocimiento intercorporal. Son gestualidades que comparte, también, quién las reconoce en un otro.

¿Cuál sería la innovación del régimen de acumulación neoliberal, según Lordon? ${ }^{2}$ Lo propio del neoliberalismo sería hacer coincidir el deseo-Amo de la institución capital, con el deseo del trabajador/a. En otras palabras: la innovación del neoliberalismo sería eliminar la mediación de la alegría por el consumo, que propiciaba el fordismo, para hacer coincidir la alegría con la misma actividad laboral, con el trabajo, que es a su vez redefinido como la fuente de realización de sí para los individuos. Esto conforma una sociedad de empresarios de sí, de auto-emprendedores que suponen que invierten en sí mismos y en otros que están a su cuidado directo de forma "libre", cuando en realidad invierten en aquellas capacidades, habilidades y valoraciones que son coincidentes con lo que se precisa para adquirir un ingreso, en economías cada vez menos basadas en relaciones salariales y cada vez más basadas en relaciones laborales flexibilizadas. En una sociedad de empresarios de sí, cada quién tiene cierta conciencia de lo que desea y cierta imaginación sobre cómo realizarlo. Pero la pregunta es qué determina al deseo a desear justamente eso y no otra cosa -algo que, en general, permanece invisible e inconsciente para los individuos de todo género- y por qué se imagina su realización como una de tipo estrictamente individualizada y hasta en competencia directa con las de los demás. O, parafraseando a Spinoza en el prefacio del Tratado Teológico-Político, la pregunta es qué lo determina a buscar la servidumbre, como si fuese su libertad (Spinoza, 1986b, p. 64).

\footnotetext{
${ }^{2}$ Entre las muchas y dispares acepciones de la palabra neoliberalismo, remito a los análisis de Michel Foucault en Nacimiento de la biopolítica. Allí, Foucault desmenuza las vertientes alemana y americana y de ésta última, la relación entre neoliberalismo y delincuencia y la teoría del capital humano. Para Foucault, siguiendo esta teoría, el neoliberalismo reconvirtió la definición de trabajo que tenía la economía clásica, para pensar el salario como la retribución por el rendimiento del capital humano, esto es: las habilidades, capacidades innatas o adquiridas, las actitudes y destrezas subjetivas que el capital pone a andar, como insumo propio, incluso producido por él. En el neoliberalismo, el actor central no es más el homo oeconomicus, sino las empresas, que son la forma que adopta cada miembro social: cada uno es un "empresario de sí" (Foucault, 2004, p. 232). Son la empresa y sus valores, sus formas de valorización y de organización la que da la forma a lo social.
} 
Qué hace desear siempre dentro de la norma (Macherey, 1990). Dice Lordon, en una aproximación a la sociología de Pierre Bourdieu (2001):

la innovación histórica del neoliberalismo consiste entonces en el proyecto de hacer entrar la movilización salarial en un régimen de afectos alegres intrínsecos: producir la alegría intransitiva del compromiso en el trabajo, tal es su nueva frontera. El trabajo no debe ser más la maldición del debilitamiento a rechazar ni incluso el medio simplemente instrumental de satisfacciones mercantiles que le siguen siendo exteriores: debe devenir una ocasión "de cumplimiento", de "realización de sí mismo" y, en el límite, de coincidencia en la felicidad de la vida profesional y de la vida a secas. Lo propio del régimen de deseos y de afectos del capitalismo neoliberal es entonces que él apuesta sobre la verdad subjetiva del trabajo como ninguno de sus predecesores (Lordon, 2018, p. 287).

Para realizar esta innovación, el neoliberalismo produce una transformación del régimen de afectos y deseos que se nutre de ciertos valores que aparecen, en general, asociados a la alegría y la libertad: la producción de la ilusión de autonomía, del manejo discrecional del tiempo, la comodidad del trabajo remoto, la indistinción entre horario de trabajo y de ocio, la posibilidad de utilizar todo tiempo como tiempo productivo (estar conectados y trabajando, mientras se viaja, se está en un parque o incluso, durmiendo). Lo central es que se busca el dominio no por el miedo (o no principalmente y en primera instancia por el miedo), sino, centralmente, por afectos derivados de la alegría: por el sentimiento de autoestima, de amor de sí, combinado con la ilusión de la libre determinación ${ }^{3}$.

${ }^{3}$ El fenómeno del "asalariado contento" con su trabajo, o mejor, del trabajo que es tomado como opción vital, no se reduce a ejecutivos y CEOs, sino a cualquiera que crea que trabaja también porque se realiza en el trabajo, más allá de las penurias que padezca o las precarizaciones y desregulaciones a las que esté sometido. Frente a este fenómeno, en general ligado a la identificación entre tiempo de trabajo y tiempo de vida, se suele señalar la alienación de los demás, de la cual nosotros no participaríamos, la servidumbre voluntaria de los otros, con excepción de la nuestra, y objetar el súbito consentimiento de los demás a la (auto)explotación, consentimiento que nosotros no daríamos. Esos señalamientos son parte de los mismos mecanismos (heterónomos) de constitución de nuestros ingenia, o complejos pasionales colectivos, que surgen de las experiencias comunes o afecciones comunes que tenemos. En otras palabras: estos señalamientos -de los cuales nos exceptuamos, porque nuestro trabajo sí sería diferente y sí valdría la pena- son parte de los mecanismos afectivos que surgen de la común exposición a este tipo de relaciones económicas, basadas en la realización individual. Lo que existe para Lordon, en cambio, no son excepciones, sino una "universal servidumbre pasional", es decir, un universal "sometimiento al encadenamiento de las causas y los efectos que determina cada una de nuestras puestas en movimiento" (Lordon, 2018, p. 296). 
A cada división del trabajo le corresponde entonces una cierta división del deseo y una cierta asignación (autoritaria, heterónoma) de objetos de fijación de esos deseos, de disposiciones a moverse en pos de algo que creemos que elegimos libremente, sin ser conscientes de qué nos determina a elegirlo. Pero ¿significa entonces que todos estamos igualmente determinados a desear eso y no otras cosas? No. Todos somos determinados por el régimen de acumulación a desear ciertas cosas, pero la distribución de los deseos se asigna según diversas cualidades sociales, que reintroducen la desigualdad en la igualdad. Reintroducen la desigualdad en la igualdad, porque están desigualmente distribuidas las posibilidades y las calidades de las alegrías disponibles. Esta asignación heterónoma se acepta, en general, por los sujetos, como si fuese parte de un orden natural.

La fijación de los enrolados, en efecto, sitúa en el camino hacia una concepción distributiva de la dominación como distribución desigual de las posibilidades de alegría. En ese sentido, "dominación" reenvía al conjunto de los mecanismos que permiten limitar a algunos, los más numerosos, a los dominios de la alegría restringida, y reservar a otros, los oligoi, los dominios ampliados de la alegría (Lordon, 2018, p. 298).

La división social del deseo se hace carne en los individuos, tornando natural cierta desigualdad en el acceso a la alegría, naturales ciertas autorizaciones a algunos disfrutes, natural la asignación y la restricción de ciertos accesos, naturales las "elecciones" de objetos de deseo y aspiraciones. Siguiendo la idea de Spinoza en el capítulo V del Tratado Teológico-Político de que nadie tolera ser gobernado por un igual (1986a), p. 158), Lordon afirma que para el dominio es necesaria la reintroducción de desigualdades imaginarias (mayores o menores, según cada régimen de acumulación). El neoliberalismo muestra la desigualdad como algo deseable: produce deseo de desigualdad, subraya la diferencia específica imaginaria de cada quién, como distancia y valorización respecto de los otros y desvaloriza la igualdad, al identificarla con homogeneidad o resto, no elegible. Pero produce también una estabilización de esas desigualdades, un cierto orden natural redivivo, en el cual acomodarse, aceptar lo que nos habría tocado y marcar a los otros que también deberían resignarse. Dice Lordon:

Es necesario entonces todo un trabajo social para disimular la igualdad real, la de esta naturaleza "una y común a todos" (Tratado político VII, 27), y recrear la desigualdad imaginaria como única capaz de hacer consentir el hecho del gobierno como los privilegios de asignación. Es esta recreación 
la que manifiesta la división del deseo, asignando imaginariamente a cada uno lo que a él se le ha permitido desear según su cualidad social (2018, p. 298) ${ }^{4}$.

Las técnicas de supuesto autogobierno que introduce el neoliberalismo, entonces, vienen acompañadas de una autolimitación, tomada como natural, hecha carne en los individuos: se asume como axioma que está naturalmente permitido a algunos disfrutar de tales alegrías y no de otras, según su condición social. Es decir, se trata de un autodominio que introyecta una cierta imagen de sí para los individuos, que será más o menos apreciada según cómo sea la pertenencia social o los éxitos en la carrera meritocrática de la vida. En los estamentos más desfavorecidos o en quiénes, pese a la aparente libertad para hacerlo, no se realicen, la imagen menospreciada de sí podría enmarcarse dentro de lo que Spinoza define como abyección, o una autolimitación del deseo por menosprecio de sí mismo. Es decir, por un afecto que es una variante del odio de sí (EIII, definición 29 de los afectos): "la abyección consiste en estimarse, por tristeza, en menos de lo justo".

Este odio de sí no se focalizará sino que, por la dinámica mimética del deseo en Spinoza, se proyectará también sobre aquellos otros a los que se ve como semejantes: si yo no puedo tal cosa, el otro semejante a mí, tampoco debe poder (E III, 20, 33 y 34). Y esto asignará a los demás sujetos sociales, por encima y por debajo, los casilleros "naturalizados" del orden social. Los ordenará en los casilleros que deben, naturalmente, aceptar. Porque como bien explica Spinoza en la definición 29 de los afectos, la abyección en sí, como la humildad, es bien extraña: en general, se aparenta la abyección cuando en general se es ambicioso o envidioso (ver también E III, 55).

\section{Odio y crisis}

Para la teoría de la regulación, el capitalismo se expresa en ciertas formas institucionales. Ellas "regulan" o estabilizan las contradicciones de cada etapa, sin eliminarlas, y esta regulación perdurará durante un tiempo indefinido -de ahí el nombre de la escuela-. Por tanto, el capitalismo se expresa en ciertas formas institucionales históricamente mutables, que estabilizan las tensiones durante un tiempo y que, necesariamente, entrarán en crisis. Por tanto, el capitalismo varía, muta, se renueva y, al hacerlo, renueva su imaginario.

\footnotetext{
${ }^{4}$ Diego Tatián dará otra lectura de la igualdad: ella no es lo dado en la naturaleza, sino que es una producción política, infundamentada, porque la naturaleza en Spinoza es infinita producción de modos singulares y diversos (Tatián,26 de noviembre de 2018).
} 
La crisis, para la teoría de la regulación, se entiende como una "transición" o remodelación de las formas institucionales, en las que el capitalismo se expresa. Estas crisis son, a la vez, una mutación de los complejos pasionales en que se expresan los regímenes de acumulación. Hay un determinado momento -no puede decirse cuándo ni por qué-, en que los individuos no prestan más obediencia a las formas institucionales vigentes, no las reconocen, trastocándolas de hecho, con variados grados de violencia. La crisis que se da entonces puede ser el paso a otro régimen de acumulación o a su destrucción.

Pero la crisis no es equivalente a percibir que algo va mal. Tampoco es equivalente a la puesta en conjunto de un cúmulo de datos objetivos, que darían cuenta de un desequilibrio económico. De hecho, el neoliberalismo ha acumulado desequilibrios que es discutible que pudieran ser interpretados como una crisis. Dirá Lordon:

el régimen de acumulación neoliberal hace ver mejor que nunca todo lo que separa analíticamente la crisis conceptualizada como ruptura de un antiguo esquema coherente de la acumulación del capital de la 'crisis-cuando-algova-mal'. El desempleo masivo, como las desigualdades o la precariedad, no son en absoluto indicios de una 'crisis' - ¿qué duraría desde hace treinta años? -; son caracteres permanentes de ese régimen, productos estables de su coherencia instalada -en efecto, desde hace treinta años...- (2018, p. 136).

¿Cuándo se produce una crisis? Para la teoría de la regulación, cuando surge una desestabilización excepcional, que la estructura no está en condiciones de acomodar. Pero esta desestabilización abre a una disputa entre fuerzas políticas, entre fuerzas que buscan profundizar la desestabilización y fuerzas que buscan reencauzarla. ¿Cuál es entonces el indicador de que se está antes una crisis y no frente a un nuevo reacomodamiento? Ninguno en particular. Es decir: qué nivel de desempleo se tolere, qué nivel de precarización, qué nivel de pobreza, depende de un umbral afectivo, que es relativo al ingenium de cada sociedad ${ }^{5}$. Hay algo -indefinible de antemano-, que cruza el umbral de lo socialmente tolerable, por encima del cual se produce lo que Spinoza calificaba de indignación: una cadena mimética, social, de un afecto de odio, que se da cuando alguien se con-mueve ante el daño que se ejerce sobre un semejante y visualiza, a la vez, la causa de

\footnotetext{
${ }^{5}$ Sobre el concepto de ingenium, ver Moreau (2009).
} 
ese daño (E III, 22, esc. $)^{6}$. Es decir, una cadena social de odio, mimética, acompañada de la imagen de quién daña al semejante y que puede llevar a la sublevación. En términos spinocistas: frente a una afección común (pongamos, medidas de austeridad reiteradas, ajustes, represión, etc.), la complexión afectiva de los individuos reacciona de una determinada manera. Pero no es hasta que se cruza un umbral, que esa afección externa produce un afecto común, un juicio común, una idea común, que genera un movimiento común de rechazo, una disposición corporal colectiva de rebelión, un pasaje al acto. Cuál sea ese umbral, es una incertidumbre política.

En otras palabras, hasta que no se forme una idea-afecto común, que congregue un activo rechazo del daño producido al semejante, o un movimiento común de indignación lo suficientemente intenso como para ahondar la desestabilización excepcional del régimen de acumulación, no habrá crisis, por más que se hable de crisis todo el tiempo. ¿Cuándo sucede eso? ¿Frente a qué nivel de desempleo; a qué ajuste; contra qué ley arra-

${ }^{6}$ La obra de Alexandre Matheron abrió una línea fecunda de reinterpretación de Spinoza en torno a la importancia del rol de la pasión de la indignación, tanto en el origen del Estado, como en la revolución, su otra cara de la moneda (Giancotti, 1977; Visentin, 2001). Primero, en el libro Individu et communauté chez Spinoza, de Matheron (1969, pp. 287-354), y luego en el artículo Le problème de l'évolution de Spinoza du Traité Théologico-Politique au Traité Politique, de 1990, donde contesta unas críticas a su lectura. La pasión de la indignación es una de las así llamadas miméticas, que son las pasiones que desatan mecanismos de emulación afectiva: cuando proyectamos que algo semejante a nosotros es afectado de tristeza o alegría, somos afectados de igual manera. La indignación es definida en el escolio de EIII, 22 como el «odio hacia aquel que ha hecho mal a otro», al cual juzgamos semejante a nosotros. Nótese que ese dañado no tiene que ser objetivamente semejante a nosotros, sino juzgado por nosotros como tal y que podemos extender el odio a quien lo daña a cualquier otra cosa, que juzguemos semejante a ella (EIII, 46). Esto genera articulaciones sociales basadas en la proyección de semejanza, a dos puntas: proyección de semejanza nuestra respecto de quien es dañado; semejanza de odio respecto de aquellos que juzgamos se parecen al que daña. Estas articulaciones sociales están sostenidas en el odio, un afecto releído en clave política, que genera un deseo, esto es, una acción determinada dirigida a «apartar» o «destruir» aquello que se odia (EIII, 13esc). Un deseo que funda unos fenómenos como el separatismo, el racismo o la formación de espacios seguros excluyentes.

Para Matheron, la irrupción de la indignación, del odio político, «lo cambia todo» en las dinámicas pasionales (Matheron, 1990, p. 264). Rompe el efecto de soledad que se tiene, o bien frente a la imagen de un tirano (como Spinoza ejemplifica en el despotismo turco), o bien por estar en una condición asimilable a la de un estado de naturaleza (es decir, en un contexto de ejercicio, sin regulación, del derecho natural de cada quien, que se extiende tanto como se extiende su potencia). La aparición de la indignación pone fin a una soledad que es social, que es inducida, ya sea por un régimen despótico que mantiene el aislamiento o por la ficción de un estado social que se asimila al estado de naturaleza. La indignación es el odio que articula socialmente a un colectivo como víctima, por efecto de la proyección de semejanza, y que troca el daño que se infligió, primero individualizado y dirigido a alguien en particular en un daño común, frente al cual debe responderse social y activamente. 
sadora de derechos? Es impredecible. Lo único cierto es la estacionalidad de las formas institucionales del neoliberalismo, a pesar de la sensación generalizada y global de malestar, a pesar de las muy cotidianas manifestaciones en contra y a pesar de los niveles de precarización crecientes. ¿Por qué la indignación social no produce un pasaje al acto, en muchos escenarios contemporáneos? ¿Por qué no se da una indignación acorde al nivel de daño? ¿Qué la obstaculiza? ¿Qué la bloquea? ¿Qué la habilita?

En base a los análisis que hemos reconstruido, quisiera plantear, como hipótesis, que el neoliberalismo combina dos tipos de movimientos de lo que, en términos spinocistas, se llamaría odio. Por un lado, produce este afecto de abyección, esta adaptación de los deseos a la imagen menospreciada de sí, de odio de sí, de humillación, que se produce cuando el individuo introyecta que su progreso y su realización dependen de sus solas capacidades e invisibiliza todo lo que, objetivamente, obstaculiza la actualización de esas capacidades. Esta abyección que tiene de sí, se proyecta a los demás que considera como semejantes o, incluso, inferiores a él, generando una clasificación social "natural", a la que cada quién debe ajustarse, y unas cadenas sociales de odio, si percibe que hay resistencia a esa adaptación: homofobia, racismo, violencia hacia migrantes, etc. Por el otro, y sumado a lo anterior, al diversificar y fragmentar en extremo las experiencias laborales, el neoliberalismo interviene sobre las experiencias comunes, esto es, sobre las afecciones comunes, invalidando la producción de una cadena de indignación lo suficientemente intensa como para generar un trastrocamiento institucional en sentido progresista (entendiendo por ello uno que ponga en el centro de lo político a la garantía efectiva del goce de derechos sociales). Es decir, aun cuando haya muchas personas vulnerabilizadas, precarizadas, etc., es difícil que ese sinnúmero pueda proyectarse y actuar como semejantes, durante un tiempo perdurable. Es la fragmentación absoluta de lo que décadas atrás se llamaba "clase trabajadora". En resumen, las combinaciones de odio son dos: por un lado, el neoliberalismo singulariza el odio o menosprecio de sí, en muchos; por el otro, impide que el malestar social se organice en acciones políticamente relevantes por un tiempo perdurable.

Quisiera detenerme en este segundo movimiento, él de bloqueo. El neoliberalismo obstaculiza al extremo la posibilidad de una cadena social de indignación lo suficientemente intensa y perdurable como para generar un trastrocamiento institucional progresista. Lo hace, primero, al fragmentar las experiencias laborales; segundo, al fragmentar la proyección de semejanzas sociales amplias y perdurables y, tercero, al multiplicar y al tornar simultáneas la percepción de causas de daño, inflacionando estas afecciones, generando un bombardeo cuasi instantáneo y continuado de 
causales de indignación e impidiendo que se dé un afecto a partir de ellas, una idea que singularice y jerarquice aquello que nos afecta y mueva a una acción relevante y perdurable en términos políticos. Produce algo así como el embotamiento que Spinoza adscribía a la imaginación, cuando ella no puede distinguir cada una de las afecciones corporales y conforma una imagen universal, inadecuada y pasiva (E II, 40, esc. 1). Entre el cúmulo de afecciones instantáneas y el afecto se abre un compás de espera, un embotamiento de la figuración, un agotamiento de la potencia cognoscente de distinguir y jerarquizar lo que sucede.

En resumen, se bloquea la producción de cadenas de indignación lo suficientemente intensas, basadas en imaginaciones de semejanza social lo suficientemente amplias, como para provocar una ruptura del régimen de acumulación. Hay malestar mayoritario, pero no necesariamente un pasaje al acto lo suficientemente extendido y perdurable como para generar un cambio social progresista. Es una gramática bloqueada (Virno, 2003). Nótese que no es que toda cadena social de odio está bloqueada: sólo la indignación que podría revertir la situación en un sentido progresista lo está, porque el deseo de los muchos está mayormente configurado a partir de una interiorización del menosprecio de sí, de los semejantes y los que se percibe inferiores, por lo que es mucho más factible que sean esos odios los que se expresen en acciones políticas.

Esta gramática de bloqueo de la indignación social progresista amplía el umbral social de lo tolerable 7 . Porque justamente, bloquea la percepción de estar ante problemas comunes, que podrían dar lugar a solidaridades sociales más amplias. ¿Qué tendrían en común un CEO, un feriante o un cuentapropista, todos enrolados bajo el término común de emprendedores? ¿Qué tendrían en común un artista y una empleada pública? ¿Cómo se movilizaría a quienes dependen para su ingreso de aplicaciones digitales impersonales, que racionalizan e individualizan al extremo el tiempo de trabajo? Probablemente puedan converger en una demostración política, pero es difícil encontrar una práctica común que haga perdurar ese encuentro contingente. Es difícil que entre ellos haya empatía, porque es difícil que proyecten semejanza y porque su sola convergencia en espacios públicos (cada vez menos públicos) o en espacios laborales (cada vez menos compartidos) es una ulterior tarea a cargarse en el ajetreo del día.

\section{Conclusiones}

\footnotetext{
${ }^{7}$ Sobre la ampliación del umbral de tolerancia, podría relacionarse esta experiencia con la apatía del público socializado en medios audiovisuales, en la contemporaneidad, que describe Silvia Schwarzböck en su libro Los monstruos más fríos (2017).
} 
Gilles Deleuze y Félix Guattari (1995, p. 36) decían que la cuestión de la filosofía política es dilucidar esta reversión del deseo de libertad en deseo de servidumbre, que aparecía en el prefacio del Tratado TeológicoPolítico. Había que poder dilucidar qué mecanismos, qué dispositivos, qué técnicas capturan el deseo, fijándolo en objetos que lo encorsetan en dinámicas repetidas y encadenantes, de modo de tornar innecesaria la represión porque en general, el deseo se ajusta a la norma. Había que analizar cómo se desea la servidumbre y ya no sólo cómo se la tolera o se la resiste. Ese es el enigma político de Spinoza, que anuda subjetivación individual y política colectiva. Este enigma se hace más acuciante desde la extensión de las formas de subjetivación del neoliberalismo, que articulan autodominio, flexibilidad laboral e imágenes de libertad individual. Con el telón de fondo de los análisis sobre el neoliberalismo que propiciara M. Foucault en Nacimiento de la biopolítica, entre otros, se puede retomar la centralidad del deseo en la obra de Spinoza, para pensar cuáles son sus condicionantes contemporáneos, cuáles son sus modulaciones y formas; y así, se puede pensar cómo se le da forma social al deseo, para que en general, no sea necesaria la represión y cómo se lo concibe y actualiza desde su positividad, antes que desde la enajenación o la alienación (Sévérac, 2017). Esto abre una línea de investigaciones actuales, situadas entre las ciencias sociales y la filosofía, entre la teoría y el análisis de casos, tiempos, historicidades y geografías concretas.

La fragmentación de la afección común de los trabajadores -o la hiperindividualización de la economía-, el quiebre de la experiencia de compartir espacio y tiempo de trabajo, tal como propiciaban las fábricas del fordismo, el desmantelamiento de los derechos sociales y la responsabilización individual por la protección y los logros en el derrotero de la vida, dificultan la conformación de una imagen colectiva de lo que antes hubiéramos llamado clase trabajadora y su accionar político duradero. Hay malestar, pero no necesariamente hay una acción política perdurable, que permita la crisis del régimen de acumulación. A la vez, se introyecta una imagen menospreciada de sí, combinado con un odio social frente a aquellos que se cree que obstaculizan el propio lugar en un orden social imaginado como jerárquico y natural (ya sea semejantes o percibidos como inferiores).

Sin embargo, no es que no se llena el vacío que esa fragmentación de la experiencia laboral produce. Los catalizadores de una identidad común en la contemporaneidad son otros: asistimos a la re-centralidad de las disputas religiosas, de las distinciones raciales, sexuales y morales y a la reaparición de nacionalismos, proclives a reintroducir intensidad y capturar en su favor, ellos sí, los movimientos de odio e indignación colectivas, que la 
subjetivación neoliberal promueve. Son ordenadores simples, en un mundo cada vez más diferenciado.

Las democracias contemporáneas se juegan su suerte en este campo.

\section{Referencias bibliográficas}

Balibar, É. (2016). De la individualidad a la transindividualidad. Córdoba, Argentina: Brujas.

Bourdieu, P. (2001). La doble verdad del trabajo. Archipiélago: Cuadernos de crítica de la cultura, (48), 53-56.

Bove, L. (2010). Espinosa e a psicologia social. Ensaios de ontología política e antropogênese. Belo Horizonte, Brasil: Editorial Autêntica.

Chaui, M. (2011). Desejo, paixão e acão na Ética de Espinosa. São Paulo, Brasil: Companhia das Letras.

Deleuze, G. y Guattari, F. (1995). El Anti-Edipo (F. Monge, Trad.). Barcelona, España: Paidós.

De Pablos Escalante, R. (2018). El deseo de razón y la alteridad constitutiva. Apuntes sobre el ser humano en la Ética de Spinoza. Revista Co-herencia, 15(28), 245269. doi: 10.17230/co-herencia.15.28.11.

Foucault, M. (2004). Nacimiento de la biopolítica. Buenos Aires, Argentina: Fondo de Cultura Económica.

Giancotti, E. (1977). Libertà, democrazia, rivoluzione in Spinoza. Appunti per una discussione. Giornale critico della filosofía italiana, (56), 358-369.

Lordon, F. (2015). Capitalismo, deseo y servidumbre: Marx y Spinoza. Buenos Aires, Argentina: Tinta Limón.

Lordon, F. (2018). La sociedad de los afectos. Por un estructuralismo de las pasiones. Buenos Aires, Argentina: Adriana Hidalgo editora.

Macherey, P. (1990). Sobre una historia natural de las normas. En E. Balbier, G. Deleuze, H. L. Dreyfus, M. Frank, A. Glucksmann y otros (Comp.). Michel Foucault, filósofo (pp. 170-185). Barcelona, España: Gedisa.

Matheron, A. (1969). Individu et communauté chez Spinoza. París, Francia: Les Editions de Minuit.

Matheron, A. (1990). Le problème de l'évolution de Spinoza du Traité Théologicopolitique au Traité politique. En E. y P. F. Moreau (Eds.). Spinoza: Issues and directions (pp. 258-270). New York, Estados Unidos: Brill.

Moreau, P. F. (2009). El concepto de ingenium en la obra de Spinoza (Pedro Lomba Falcón, Trad.). Ingenium. Revista de historia del pensamiento moderno (1), 3-12.

Schwarzböck, S. (2017). Los monstruos más frios: estética, después del cine. Buenos Aires, Argentina: Mardulce.

Sévérac, P. (2017). Le devenir actif chez Spinoza. París, Francia: Honoré Champion.

Spinoza, B. (1980). Ética. Madrid, España: Orbis Hyspamérica. Publicado originalmente en 1675 . 
Spinoza, B. (1986a). Tratado político. Madrid, España: Alianza. Publicado originalmente en 1677.

Spinoza, B. (1986b). Tratado Teológico-político. Madrid, España: Alianza. Publicado originalmente en 1670.

Tatián, D. (26 de noviembre de 2018). La igualdad como 'construcción de la política'. Página/12. Recuperado de https://www.pagina12.com.ar/157974-laigualdad-como-construccion-de-la-politica

Virno, P. (2003). Gramática de la multitud. Para un análisis de las formas de vida contemporáneas. Buenos Aires, Argentina: Colihue.

Visentin, S. (2001). La libertà necessaria. Teoria e pratica della democrazia in Spinoza. Pisa, Italia: ETS. 